minutes, evidencing that goal setting does work and doesn't take a long time. ${ }^{2}$ While prevention is a significant topic in dentistry; it doesn't have to be a massive undertaking for patients. We can keep our advice simple, specific, and realistic. Small things like 'spit, don't rinse' and keeping snacks to mealtimes can shift things in the right direction.

SDCEP offers a practical acronym to plan how we offer this advice, 'TIPPS' meaning to 'talk, instruct, practise, plan and support'.

A mantra that has always resonated with me is 'Small but massive', the tagline of Glasgowbury, a charity based close to where I live. ${ }^{4}$ For me, it encapsulates how 'small' actions can have a 'massive' effect. Where would Sisyphus be if he spent time breaking the boulder down into smaller, more manageable pieces and planned to take it up, piece by piece? Using motivational interviewing and forming action plans for patients represents a shift from 'judgemental lecturing' to empowering patients. After all, we can't push the patient up the hypothetical hill ourselves; instead, we're supporting them to reach the top.

The mantra of 'small but massive' also coincides with the ethos of minimally invasive dentistry, ensuring that we preserve tooth tissue during operative dentistry and prevent further carious lesions. As students learning, it's easy to see glamorous before and after Instagram photos of smile makeovers and dream of doing something similar in the future. Yet, we forget about the massive change we can affect now. Veneers, composite, and crowns can change a smile for the lifetime of that material but helping to modify a patient's attitude to oral health can change a smile for life.

\section{References}

1. Scottish Intercollegiate Guidelines Network (SIGN). Dental interventions to prevent caries in children. Edinburgh: SIGN; 2014. (SIGN publication no. 138).

2. Sniehotta F F, Araújo Soares V, Dombrowski S U. Randomised Controlled Trial of a One-minute Intervention Changing Oral Self-care Behaviour. J Dent Res 2007; 86: 641-645.

3. Scottish Dental Clinical Effectiveness Programme. Oral Hygiene TIPPS video. Available online at: www.sdcep.org uk/published-guidance/periodontal-management/oralhygiene-tipps-video/ (accessed April 2021).

4. Glasgowbury. About Glasgowbury. Available online at: www.glasgowbury.com/contact/about-glasgowbury/ (accessed April 2021).

\title{
CHANGE - HOW FAR CAN WE REALLY GO?
}

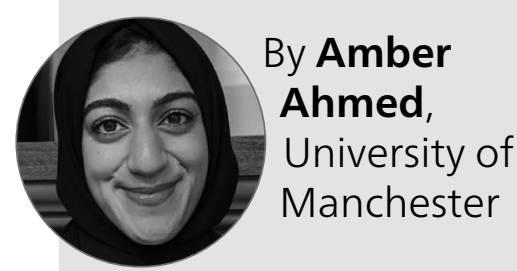

We are living in an era, where everything is constantly changing. The earth is heating up and we are demanding world leaders to listen. Yet, despite of this revolution of change, new statistics on childhood tooth decay in the UK suggest a concerning lack of progress.

In 2019, Public Health England stated 1 in 4 (23\%) of 5-year-olds have previously had dental decay. ${ }^{1}$ These findings are identical to the results of the previous survey conducted in 2017. No progress has been made towards tackling this unacceptable level of tooth decay in England.

These figures are hard to digest when considering the heart-shattering consequences of tooth decay on a child's quality of life. An average of 3 days of school were missed due to dental problems. $38 \%$ of children had sleepless nights because of the pain. Many days of work were potentially lost as $41 \%$ of parents/carers were employed. ${ }^{2}$

Surely, these figures reveal that our current efforts towards changing the numbers are not working. And that despite of our hard work, the change we wish to see is limited. And this begs the question, how far can we really go?
It's so often that I see a child sitting in a pram holding a packet of crisps with a fizzy drink in hand. The constant bombardment of advertisements showcasing sugary snacks on TV has created a culture of sugary snack eating, the norm. How strange would it be to turn up to the cinema and be served an apple at the cashier? Exactly, we couldn't even dream of it.

\section{'I'm not suggesting that we eradicate sugar from children's diets. But what I am suggesting is a push for society to implement these measures.'}

Evidently, something needs to change.

I'm not suggesting that we eradicate sugar from children's diets. But what I am suggesting, is a push for society to implement these measures. Time and time again, we have addressed our concerns to the government to help tackle this issue. We have been unsuccessful. To succeed, we must do it ourselves.

We all have family, friends, peers, known connections and even strangers in our lives. What I suggest is, alongside our promotion of oral health, we become leaders in our society to bring this wave of change. A survey of 209 employees and supervisors was conducted to test how effective the role of leadership played in stimulating employees to support change. This was measured through supervisor ratings of employee behaviour.

As predicted, results showed that leadership was more effective in building a support for change and that change was greatly accepted where the leaders communicated a vision of continuity effectively. This vision of continuity instilled a sense of continuity of organisational identity in employees. ${ }^{3}$

We all have a duty towards our patients to help them as best as we can. We must do so through communicating an appealing vision of this change in order for society to embrace it. Until we can assure people that we will preserve their identity, the numbers will inevitably remain the same.

\section{References}

1. GOV.UK. Official Statistics Oral health survey of 5-year-old children 2019. March 2020. Available online at: www.gov.uk/government/statistics/oral-healthsurvey-of-5-year-old-children-2019 (Accessed February 2021).

2. GOV.UK. Guidance Child oral health: applying All Our Health. August 2019. Available online at: www. gov.uk/government/publications/child-oral-healthapplying-all-our-health/child-oral-health-applyingall-our-health (Accessed February 2021).

3. Venus M, Stam D and van Knippenburg D. Research: To Get People to Embrace Change, Emphasise What Will Stay the Same. August 2018. Available online at https://hbr.org/2018/08/research-to-get-people-toembrace-change-emphasize-what-will-stay-the-same (Accessed February 2021). 